\title{
Determinants of Food Insecurity According to the Calorie Intake Approach: A Specific Case in South Kivu, DRC
}

\author{
Vwima Ngezirabona Stany ${ }^{1, *}$, Bumva Birakaheka Judical ${ }^{1}$, Mushagalusa Nachigera Gustave ${ }^{2}$ \\ ${ }^{1}$ Department of Rural Economic, Evangelical University in Africa (EUA), Bukavu, DRC \\ ${ }^{2}$ Department of Agronomy, Evangelical University in Africa (EUA), Bukavu, DRC
}

Email address:

svwima@uea.ac.cd (V. N. Stany)

${ }^{*}$ Corresponding author

\section{To cite this article:}

Vwima Ngezirabona Stany, Bumva Birakaheka Judical, Mushagalusa Nachigera Gustave. Determinants of Food Insecurity According to the Calorie Intake Approach: A Specific Case in South Kivu, DRC. International Journal of Applied Agricultural Sciences.

Vol. 7, No. 4, 2021, pp. 190-202. doi: 10.11648/j.ijaas.20210704.18

Received: November 16, 2020; Accepted: November 27, 2020; Published: August 27, 2021

\begin{abstract}
This study aims to measure food insecurity and its correlates according to the calorie intake approach. By conducting the consumption survey on a stratified sample grouped into localities considered, here, as strata. The survey covered 139 households. The results show that $84.2 \%$ of the respondents generate their income from agriculture and the household lives on US \$ 50.09 per month obtained from the optical expenditure. Households allocate more than $50 \%$ of this income to food consumption. The calorie intake provided by the consumed food is $1248.28 \mathrm{kcal}$. The Estimated Energy Need (EEN) calculated was $2303.76 \mathrm{kcal}$ on average, i.e., a negative gap of 1055.48. The estimated results of the LOGIT model for the possibility of being food secure showed that factors of various kinds expose households to food insecurity, i.e., level of education, gender, income and number of meals. In addition, livestock farming, distance from home to market were variables that significantly condition the probability of a household being food secure only in the locality of Bwegera whereas household size and existence other income sources within the household significantly affect food security only in the locality of Lemera. In this case, it is necessary to encourage large-scale production through access to new technologies, access to food, education and financing, structuring and strengthening the capacities of farmers' organizations, diversification of activities and the revival of the livestock farming sector and its integration into the cropping system, access to resources by women, the development of agricultural markets for products and inputs.
\end{abstract}

Keywords: Food Security, Calorie Intake, Monetary Poverty

\section{Introduction}

Agriculture is the main occupation of the population of Uvira territory but, according to Ansoms and Marivoet [1], it is, with Kalehe, the poorest territories. The choice of this study is justified by the idea of authors who support the importance of the factor "accessibility to food" in the food security of a household. According to Sen [2], "If a person lacks means to acquire food, the presence of food on the markets is not a great consolation." Food security is ensured when all people, at all times, have economic, social and physical access to sufficient, safe and nutritious food that meets their nutritional needs and dietary preferences to enable them to lead active and healthy lives [3], By this definition, the achievement of food security remains a major challenge in a world where approximately 795 million people are still undernourished, representing $13 \%$ of the world's population [4]. This figure amply demonstrates the extent of the food security problem, whose long-term consequences are the deterioration of the quality of social well-being for the vast majority of populations [5].

Food security is "access for every individual at all times to food resources for a healthy and active life" [6]. For the Ontario Public Health Association, "People are living in a food secure situation when they are able to buy enough safe, healthy, and enjoyable food to ensure their good health. The way they obtain these foods should help them preserve their pride and their family's one" [7]. This definition takes into account the four dimensions or components of food security, which are: the availability of good sanitary and nutritional 
quality foods, the accessibility of the latter for a population, including the most vulnerable, the optimal use of food by individuals and stability of supplies in space and time [8].

Food insecurity refers to the situation of people who are below the threshold required to eat from their own production and / or annual income and who are forced to consume their savings, sometimes either to sell their production means or to solicit solidarity [9]. For Azoulay and Dillon [10], food insecurity is a genetic term that encompasses all situations where people suffer or are at risk of suffering from hunger, that is, malnutrition or famine. According to Tarasuk et al. [11], measuring and monitoring food insecurity in the country focuses on a household's experience of food insecurity or inadequate or uncertain access to food due to lack of financial resources.

Food insecurity may include the fear of lack of food before there is money to buy more, the inability to eat balanced meals, being hungry, missing meals and, in the extreme, absolute deprivation of food for a whole day because of lack of food and money to buy food. For FAO [8], food insecurity can be chronic when people are not able to meet their nutritional needs over a long period of time or transient. The same typology of food insecurity is found in Ouedraogo et al. [9], who define chronic food insecurity as the state of a group of individuals and groups who are permanently poorly nourished and unable to meet their nutritional needs on an ongoing basis. These individuals and groups do not produce or buy the food they need, in sufficient quantity or quality, and temporary insecurity, which makes it impossible for individuals and groups to temporarily meet their nutritional needs. The instability of their production or prices is very often the main cause.

Tarasuk et al. [11] discuss three types of food insecurity, namely: marginal food insecurity which is the fear of lack of food and / or limitation of food selection due to lack of money, moderate food insecurity which is reached when the quality and / or quantity of food is compromised because of lack of money, and the severe food insecurity that is reached when meals are skipped, food consumption is reduced and, to the extreme, when there is deprivation of meals for a full day or more.

The United Nations, through the SDGs, has set itself as Goal 2, to reduce hunger to zero by 2030 . To achieve it, the problem of food insecurity in the world must then be a priority and is the subject of a cycle of reflection especially that access to food, according to the Universal Declaration of Human Rights in Article $25^{1}$, has become a right recognized to all men and women all over the world by many international legal instruments. Food production continues to grow at a faster rate than the population [12]; that is why hunger is declining in the world, it has decreased by $21.4 \%$ in 25 years and people around the world have more access to grains, meat, dairy products, fruits and vegetables. Even fish

1 Article 25 of the Universal Declaration of Human Rights stipulates that "everyone has the right to a standard of living adequate for the health, well-being and the well-being of his family, especially for food, clothing, housing, medical care as well as social services needed" production is increasing, thanks to significant progress in fish farming $^{2}$. This is contrary to the Malthusian view who predicted that food production would fail to meet the needs of humanity.

If hunger increases in some parts of the world, as in SubSaharan Africa, the problem lies in distribution and not in production $^{3}$. It is not enough to produce, but it must also be well organized so that the food produced in the world arrives regularly and at a price acceptable to all consumers, wherever they live [13]. The lack of international solidarity when it comes to agricultural technology transfer, coupled with corruption, war, natural disasters and the lack of democratic institutions all contributed to the reality of empty plates ${ }^{4}$. To this can be added the land conflicts and current plant diseases [14] and the increase in prices of agricultural products internationally [15].

According to the World Bank report, $80 \%$ of the world's population have $20 \%$ of the world's income and are the only ones (the richest of the population) who reach consumption levels that cover their minimum nutritional needs. It is in the countrysides that the problem of poverty is more serious. With insufficient income available to the rural population, the supply of food in sufficient quantities is increasingly mortgaged [16]. With a $23.2 \%$ increase in hunger in SubSaharan Africa ${ }^{5}$, the food security situation and prospects show a gap that continues to increase between consumption and nutrition needs and food availability.

Despite its immense agricultural potential, the food security situation in the DRC remains precarious. The food insecurity rate is estimated at $64 \%$ [17] and $57.8 \%$ of people living in the DRC have poor or limited food consumption [18] and the number of people in acute food crisis is estimated at 5.4 million [19]. According to the 2011 IFPRI report, the DRC's Global Hunger Index (GHI) has increased by $63 \%$ [36]. This dynamic makes the Congolese population increasingly vulnerable to food insecurity characterized by the collapse of national agricultural production [20,21], food dependence from the foreign [22] and a food consumption corresponding to $1650 \mathrm{kcal}$ per person per day against a minimum requirement of $2400 \mathrm{kcal}$ per person per day [23].

According to the UNICEF Humanitarian Action report, chronic malnutrition among children under 5 years of age is increasing from $38 \%$ in 2009 to $43 \%$ in 2016 . This malnutrition is one of the main causes of mortality in the DRC and especially in the province of South Kivu, long wounded by wars and insecurities. Several problems are at

2 //www.contrepoints.org/2013/11/29/148055-la-production-agricole-mondialecontinue-daugmenter-malgre-des-predictions-alarmistes-de-declin. [Accessed August $1^{\text {st }}, 2017$ at 1:01PM]

3 http://www.cite-sciences.fr/fr/ressources/bibliotheque-en-ligne/dossiersdocumentaires/nourrir-le-monde-en-2050/4-notions-pour-comprendre-nourrir-lemonde/ [Accessed August $2^{\text {nd }}, 2017$ at 11:47Am]

4 http://parisinnovationreview.com/2010/06/29/paradoxe-autosuffisancealimentaire-mondiale-un-milliard-de-personnes-ont-faim/ [Accessed August 1st, 2017 at 11:50 AM]

5 //www.contrepoints.org/2013/11/29/148055-la-production-agricole-mondialecontinue-daugmenter-malgre-des-predictions-alarmistes-de-declin. [Accessed August 1st, 2017 at 1:01PM] 
the root of food insecurity in South Kivu, including the lack of infrastructure, especially roads, wars and insecurities, population growth (3\% in 2010), lack of technological innovation, and low income of the population, land etc. These problems are particularly acute in rural areas of South Kivu province [14], in general, and in the localities of Lemera, Kigwena and Bwegera in the Terrirory of Uvira, long regarded as the breadbasket of the province. In this work, the authors tried to analyze food security in rural households in Lemera, Kigwena and Bwegera localities.

\section{Methodology}

\subsection{Data from the Study}

The data of this study were collected from the questionnaire in June and July 2014. Three investigators were used for this work. Three localities were the subject of this survey (Bwegera, Kigwena and Lemera). Altitude was the criterion that led to the choice of these three localities. Bwegera (Kakamba Grouping) is a low-lying locality, Kigwena (Lemera Grouping) is located at medium altitude and Lemera (Lemera Grouping) at high altitude. Stratified and systemic sampling was used to investigate households grouped into villages that make up the different localities. These villages were considered as strata. The systematic draw was that heads of households were taken from the total population following an arithmetic progression. The basis of this was chosen at random and the reason was calculated to cover the entire population of reference. The strata are composed of all villages in the three selected localities (Bwegera, Kigwena and Lemera). The methodology applied to the survey is based on a two-stage probabilistic survey with the villages as primary units and the households from the selected villages as secondary units. Based on the list consulted at the village level, all households have the same probability of appearing in the sample. As shown in Table 1, the survey covered 139 households, including 63 households in Bwegera, 41 households in Kigwena and 35 households in Lemera. The first household surveyed was spaced on both sides to cover the entire village. Quantitative and qualitative methods were used to collect data in households.

Table 1. The sample calculation in the strata.

\begin{tabular}{|c|c|c|c|c|c|c|c|c|}
\hline \multicolumn{3}{|c|}{ Bwegera locality } & \multicolumn{3}{|l|}{ Kigwena locality } & \multicolumn{3}{|l|}{ Lemera locality } \\
\hline Villages & Household size & Sample size & Villages & Household size & Sample size & Villages & Household size & Sample size \\
\hline Kibomboza & 471 & 14 & Musholo & 86 & 3 & Nakachoma 1st & 141 & 4 \\
\hline Lupango & 409 & 12 & Narunanga & 312 & 9 & Nakachoma 2nd & 27 & 1 \\
\hline Rugenge & 271 & 8 & Rubanga centre & 330 & 10 & Lemera centre & 267 & 8 \\
\hline Aceko & 376 & 11 & Ndare & 154 & 5 & Mulamba 1st & 77 & 2 \\
\hline Cepac & 93 & 3 & Rubenga & 120 & 4 & Mulamba 2nd & 190 & 6 \\
\hline Mupando & 307 & 9 & Simba & 318 & 10 & Bwagwa 1st & 177 & 5 \\
\hline \multirow[t]{3}{*}{ Naruhuhuma } & 186 & 6 & & & & Bwagwa 2nd & 197 & 6 \\
\hline & & & & & & Kishagala & 83 & 2 \\
\hline & & & & & & Simba & 40 & 1 \\
\hline Subtotal & 2113 & 63 & Subtotal & 1320 & 41 & Subtotal & 1199 & 35 \\
\hline
\end{tabular}

Source: Authors based on data from each locality.

On the basis of the survey questionnaire, the following information was collected: socio-demographic characteristics, resource endowment, economic activities, food security indicators, wealth, livelihoods. The qualitative survey consisted of organizing interviews with several other actors working in the field of food security, namely the heads of local NGOs, the village chiefs, the head of the groups.

\subsection{Data Analysis}

The data were entered in Excel, and imported in XLSTAT version 2014 to be processed. In order to understand the socio-economic characteristics of the households studied on the basis of the collected data, it was initially necessary to carry out an exploratory analysis based on descriptive statistics (average, standard deviation, median, maximum, minimum coefficient of variation) and tables and graphs of the data collected are made using descriptive statistics (average, median). Two approaches were used in this study. First, it was necessary to determine the food consumption level of each household for identifying households that are food insecure and their opposites, and secondly, to determine the socio-economic factors that determine the nutritional status of households.

To determine the nutritional status of households, we started from the consumption basket that was converted into calorie intake per person per day, taking into account body weight by sex and age group using the table proposed by FAO. This information was used to determine the proportion of insecure and food secure people in our study population. To find the determinants of food insecurity, the Logit model was used. The choice of this model was inspired by several authors including Zoyem et al. [24] who measured and determined the various factors of food insecurity in Burundi according to the calorie intake approach; Bucekuderhwa and Mapatano [25] who tried to understand the dynamics of vulnerability to food insecurity in South Kivu and Kinimo [26] who worked on the determinants of household malnutrition in Ivory Coast: the case of Central and Central East Regions.

Several reasons support the choice of this Logit model, notably: when the explanatory variables are not normally distributed, the estimators of the Logit model are more robust 
than those obtained by the discriminant analysis and the Logit models allow simple calculations. In addition, several authors show that the estimates of the parameters and their accuracy obtained by the Probit models are generally not very different from the Logit models [26].

Since the variable explained in the Probit model is not a quantitative coding associated with the realization of an event (as in the case of the linear specification), but the probability of occurrence of this event, conditionally on the exogenous variables, the following model was considered:

$$
\mathrm{pi}=\operatorname{Prob}(\mathrm{Yi}=1 \mid \mathrm{Xi})=\mathrm{f}(\mathrm{Xi} \beta)[27]
$$

The Probit model corresponds to the distribution function of the reduced normal centered law. Thus for a given value of the vector of the exogenous and the vector of the parameters $\beta$, the model defines the probability as the value of this function.

$$
\mathrm{p}_{\mathrm{i}}=\Phi\left(\mathrm{X}_{\mathrm{i}} \beta\right)=\int_{-\infty}^{\mathrm{X}_{\mathrm{i}} \beta} \frac{1}{\sqrt{2 \pi}} \mathrm{e}^{-\frac{\mathrm{Z}^{2}}{2}} \mathrm{dZ} \forall_{\mathrm{i}}=1, \ldots, \mathrm{N}
$$

In the case of the degree of food security, the variable $\mathrm{Zi}$ takes two alternatives, namely $\mathrm{Zi}<0$ where we observe $\mathrm{Yi}=0$ when the difference between the calories of the food basket consumed by the households and the minimum caloric requirements is negative, i.e. $\mathrm{Zi}>0$ where we observe $\mathrm{Yi}=1$ when the gap between the calories in the food basket consumed by households and the minimum caloric requirements is positive. Thus:

$$
\mathrm{Yi}=0 \Leftrightarrow \mathrm{Zi}<0 \text { et } \mathrm{Yi}=1 \Leftrightarrow \mathrm{Zi}>0
$$

More theoretically, the explanatory model $\mathrm{Y}$ postulates a relation of the type: $\mathrm{Z}=X i \beta+\varepsilon$ where $\mathrm{Xi}$ is a set of explanatory variables, $\beta$ the coefficients assigned to them and $\varepsilon$ the residual. From the above, we will therefore test the probability that households reach food security, i.e., $\mathrm{pi}=\mathrm{P}[\mathrm{Yi}=1]=\mathrm{P}[\mathrm{Zi}>0]$. Inversely, $\mathrm{pi}=\mathrm{P}[\mathrm{Yi}=0]=\mathrm{P}[\mathrm{Zi}<0]$.

More specifically, the model was considered adapted to our subject and the contexts of our study environment.

\section{$\mathrm{SA}=\alpha+\beta_{1} \mathrm{TAYM}+\beta_{2} \mathrm{NIVET}+\beta_{3} \mathrm{SEXE}+\beta_{4} \mathrm{AGE}+\beta_{5} \mathrm{MZOMARC}+\beta_{6} \mathrm{STOK}+\beta_{7} \mathrm{ELVR}$ $+\beta_{8}$ RVNU $+\beta_{9}$ REPA $+\beta_{10}$ ANCIA $+\beta_{11}$ DPAS $+\beta_{12}$ EPRG $+\beta_{13}$ OTRSRV}

Thirteen exogenous variables were used to explain the endogenous variable "Food Security".

\subsubsection{Dependent Variable: Food Security (SA)}

The sum of the calories provided by the different products consumed by the household minus the Estimated Energy Need (EEN) gives the calorie difference. This difference is positive if the calories available in the household are higher than the EEN (household food security), and otherwise, it is negative (household food insecurity).

\subsubsection{Independent Variables}

Size (TAYM) refers to the number of people in the household at the time the study was conducted. Size negatively influences household food security. Larger households will therefore be more likely to be food insecure. In this case, the hypothesis $\beta_{1}<0$ is accepted.

Education Level (NIVET) refers to the level of education of the household head. The level of education variable also positively influences food security. In this case, the hypothesis $\beta_{2}>0$ is accepted. The higher the household head is at a high education level, the more likely the household is to be food secure.

Gender (SEX) refers to the sex or gender of the household head. Gender has a positive influence on food security, that is households managed by women are more likely to be food secure than those managed by men. In this case, the hypothesis $\beta_{3}>0$ is accepted.

Age (AGE): This is focused on the age of the household head. Adult household heads are inclined to manage the household well, take a greater risk of working and have higher labor productivity than heads of young households. Thus, the hypothesis $\beta_{4}>0$ is accepted.

Distance from home to market (MZOMARC): It refers to the distance that the household head travels to buy food from the market. This factor is a very important because the longer the distance is between the house and the market, the less chance you have of physically accessing to food, the more likely you are to get food insecure. Thus, the assumption $\beta_{5}<0$ is accepted.

Stock (STOCK) refers to the existence of food stocks at the time of the survey. This variable is more important and influences food security because a household that does not stock food is more likely to be insecure than a household that stores food. In this case, the hypothesis $\beta_{6}>0$ is accepted.

Livestock farming (ELVR) refers to the households that practice breeding during the period of our study. A household that practices breeding is more likely to be food secure than a household that does not do it. In this case, the hypothesis $\beta_{7}>0$ is accepted.

Income (RVNU) refers to the monthly income of a household. A household with low monthly income is more likely to be food insecure than a household with sufficient income. Thus the hypothesis $\beta_{8}>0$ is accepted.

Number of meals consumed per day (REPA) refers to the number of meals a household consumes per day. The more a household consumes more than one meal is more likely to be food secure than a household that consumes one meal per day. In this case, the hypothesis $\beta_{9}>0$ is accepted.

Seniority in agriculture (ANCIA): It refers to seniority in agriculture. A household head who has seniority in agriculture is more likely to be food secure. In this case, the assumption $\beta_{10}>0$ is accepted.

Household food expenditure (DPAS): It refers to the household food expenditure. A household which allocates a large part of its budget to food stands less chance in food security. In this case, the assumption $\beta_{11}<0$ is accepted.

Savings (EPRG) refers to household savings. A saving household is more likely to be food secure. In this case, $\mathrm{X}=1$ is the saving household and $\mathrm{Y}=0$ is the household that does 
not save. Thus, the hypothesis $\beta_{12}>0$ is accepted.

Other sources of income (OTRSRV): This refers to another source of income. A household with multiple sources of income is more likely to be food secure. In this case, the assumption $\beta_{13}>0$ is accepted.

Table 2 shows the description of the independent variables.

Table 2. Variables Description.

\begin{tabular}{|c|c|c|}
\hline Variables & Characteristics & Description \\
\hline Size & $\begin{array}{l}\text { Quantitative Variable } \\
\text { (Number) }\end{array}$ & Only the number of the household head dependents are counted \\
\hline Education Level & Qualitative Variable & $\begin{array}{l}\text { Illiterates }(X=0) \text {; Primary }(X=1) \text {, Secondary }(X=2) \text { And Higher Academic/University } \\
(X=3)\end{array}$ \\
\hline Sex & Qualitative Variable & Binary Variable With: Female $=1$ And Male $=0$ \\
\hline Age & Quantitative Variable (Year) & Age of the household head \\
\hline Distance From Home To Market & Quantitative Variable (Km) & Distance travelled by a household head to buy food from the market \\
\hline Livestock Farming & Qualitative Variable & If the household raises animals $(X=1)$; If $\operatorname{Not}(X=0)$ \\
\hline Income & Quantitative Variable & Monthly Amount earned by the household head (Here, Optics Expenditure Was Used) \\
\hline Daily Consumed Meals & Quantitative Variable & Number of daily meals consumed by the household members \\
\hline Seniority in Agriculture & Quantitative Variable & Number of seniority that the household head has in the agriculture career \\
\hline Household Food Expenditure & Quantitative Variable & They only take into account food-related expenses \\
\hline Savings & Quantitative Variable & If the household saves $(X=1)$; Otherwise $(X=0)$. \\
\hline Other Income Sources & Qualitative Variable & If the household has multiple income sources $(X=1)$; If only one source of income $(X=0)$. \\
\hline
\end{tabular}

Source: personal analysis of the author

\subsection{Estimated Energy Need Measure (BEE)}

Estimated Energy Need (BEE) is defined as the average dietary energy intake that is expected to maintain energy balance in healthy individuals [28]. It is calculated taking into account age, sex, weight and level of physical activity (or activity coefficient (CA). Already in 1919, Harris J. A. and Benedict F. G. had empirically developed the basic metabolism formula for defining caloric needs. For them, the level of basic metabolism (MB) is the amount of energy needs of the human body, not to mention the extra energy needed for any physical activity. That is, the minimum daily energy use that allows the body to survive. This formula was refined by other scientists such as Roza and Shizgal [34] and the Institute of Medicine of National Academies (IMNA) [35]. In this article the equations from IMNA cited by Blanchet et al. [28] were used to estimate the energy needs of the population in our study area and the Activity Coefficient (CA) will be 1.2 for a minimum activity, 1.375 for a low activity, 1.55 for an average activity, at 1.725 for a high activity and 1.9 for a very high activity:

Women: $\mathrm{EEN}=354-(6,91 \mathrm{x}$ age [years] $)+\mathrm{CA} \times[(9,36 \mathrm{x}$ weight $[\mathrm{kg}])+(726 \mathrm{x}$ height $[\mathrm{m}])]$

Men: $\mathrm{EEN}=662-(9,53 \mathrm{x}$ age $[$ years $])+\mathrm{CA} \times[(15,91 \times$ weight $[\mathrm{kg}])+(539,6 \mathrm{x}$ height $[\mathrm{m}])]$

\subsection{Estimation and Income Inequality}

Since it was difficult to estimate income, the expenditure approach was used considering that all income was spent. This approach is much more widely used in countries dominated by the informal economy in which most incomes are not reported. Income inequalities were measured by the Gini coefficient and visualized by the Lorenz curve. The index or the coefficient of Gini is between 0 and 1 (or between 0 and 100 if the results are multiplied by 100). In case of perfect equality, it is equal to 0 . In case of total inequality, it is equal to 1 . Therefore, as this coefficient increases from 0 to 1 , the inequality of the distribution increases. However, there are several formulas for calculating the Gini coefficient. We will adopt one of the most used which is given in the explanatory note of the World Bank for the calculation of the inequality of the distributions, sometimes called "formula of BROWN".

This formula is written:

$$
G=1-\sum_{i=1}^{n}\left(X_{i}-X_{i-1}\right)\left(Y_{i}-Y_{i+1}\right)
$$

Where $\mathrm{X}$ is the cumulative part of the population, and $\mathrm{Y}$ is the cumulative part of the mass to be distributed. In this case, as the data are known individually, this formula can be simplified to:

$$
G=1-\frac{1}{n} \sum_{i=1}^{n}\left(Y_{i}-Y_{i+1}\right)
$$

Where $\mathrm{n}$ is the number of statistical units (the population). Note that formulas (1) and (2) give the same result.

\section{Presentation of the Results}

\subsection{Characteristics of the Respondents}
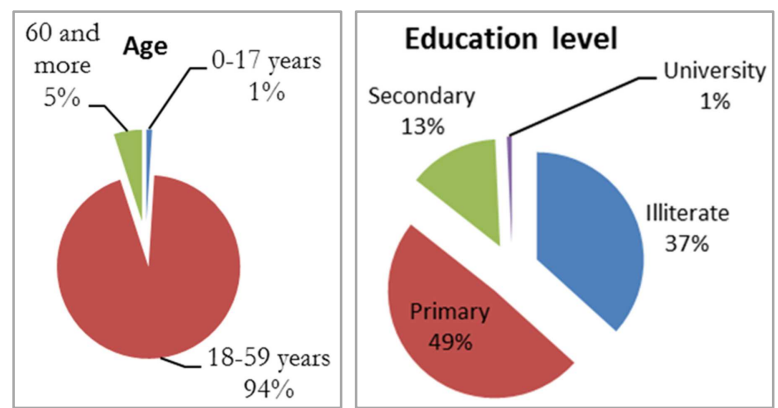

Figure 1. Distribution of respondents according to the age and education level. 
Table 3. Distribution of respondents by type of activity, sex and type of habitat by locality.

Type of habitat by locality

\begin{tabular}{lllll}
\hline \multirow{2}{*}{ Activity } & Sex & & \multirow{2}{*}{ Total } & \% \\
\cline { 2 - 3 } & $\mathbf{F}$ & $\mathbf{M}$ & & 84,2 \\
Agriculture & 86 & 31 & 117 & 5,0 \\
Commerce & 3 & 4 & 7 & 3,6 \\
Military service & 0 & 5 & 5 & 2,2 \\
Teaching & 1 & 2 & 3 & 5,0 \\
Others & 3 & 4 & 7 & 100 \\
Total & 93 & 46 & 139 & \\
\hline
\end{tabular}

Activity and sex

\begin{tabular}{lllll}
\hline Locality & Stew bricks & Heated bricks & Thatched house & Total \\
\hline Bwegera & 32 & 0 & 31 & 63 \\
Kigwena & 23 & 0 & 18 & 41 \\
Lemera & 29 & 2 & 4 & 35 \\
Total & 84 & 2 & 53 & 139 \\
$\%$ & 60,4 & 1,4 & 38,2 & 100 \\
\hline
\end{tabular}

The majority of the respondents had a chronological age varying between 18 to 59 years, i.e. $94 \%$, which is justified by the fact that a large number of respondents are household heads who are supposed to be adults. This age group supports young and old. This age group is called upon to procreate and to have activities to degenerate the income necessary to satisfy the food needs and others. The survey shows that $84.2 \%$ of respondents are farmers, of which $73.5 \%$ are women and $26.5 \%$ are men. This situation can be justified by the fact that agriculture is the dominant activity in our study environment. The predominance of women as household heads is much more justified by the fact that food production in most rural areas of African countries is a women's issue and they are the guarantors of household food security. Other activities are less and less practiced and she is found everywhere on all jerseys in the value chain of agricultural products. They are also visible in the small trade, especially agricultural products. The illiterate rate is $36.69 \%$, of which women have a high proportion $(33.81 \%)$ than men $(2.88 \%)$. This situation can be explained by the cultural weight which seeks to promote boys' school education much more than that of girls. The survey showed that at the primary school level, girls $(30.93 \%)$ study to a larger extent than men (17.98\%). This rate of women decreases at the secondary level because of early marriages and the culture itself. It reflects reality because, if a girl finishes primary school and she already knows how to read and write Swahili, culturally, she goes about housework, babysitting and helping her mother work in the fields. It is noticed that the higher the altitude is, the rate of illiterates decreases. Of the $36.69 \%$ illiterates, respectively $21.58 \%$ in Bwegera, $10.8 \%$ in Kigwena, and $4.31 \%$ in Lemera, and the higher the altitude is, the rate of primary education increases. Of the $48.92 \%$, the locality of Bwegera holds $24.24 \%$ of the people of primary level, that of Kigwena $15.10 \%$ and Lemera $9.58 \%$. Compared to other localities, these two results suggest that a large number of intellectuals are found in the locality of Lemera where some academics can even be counted. This is explained by the presence of several schools, a Reference General Hospital of the $8^{\text {th }}$ Community of Protestant churches in Central Africa and the one of white missionaries who made a positive impact on intellectual development in Lemera. While the locality of Bwegera is crossed by a main road (NR5), its high rate of illiterates is explained by the fact that, quite a lot of parents find their interests in livestock farming than in studies. It is for this reason that they prefer sending the children to keep watch over the cows than attending a school. There are few children who finish primary school. This study shows that the stew bricks houses occupy a high proportion $(60.43 \%)$ compared to others, including the locality of Bwegera (22.30\%), followed by the locality of Lemera $(20,86 \%)$ and finally that of Kigwena $(16.54 \%)$. This again testifies the difficult standard of living and the low level of development of all these localities. The only heated brick houses found in Lemera reflect the presence of missionaries and the Lemera Reference Hospital, which was once one of the best and tallest hospitals in the South Kivu province.

\subsection{Analysis of Household Production and Income}

\subsubsection{The Production Area, Production and Average Self-Consumption of Crops Grown by Households}

Based on the results, we find that out of 289 households that practice different crops in our study area, an average land area of $368.91 \mathrm{~m}^{2}$ per household has been cultivated and we notice an average production of $16618.2872 \mathrm{~kg}$ of which cassava is the most widespread crop (45.32\%) and occupies a large part of agricultural area $\left(114.60 \mathrm{~m}^{2}\right)$. The cassava holds a cultural and ancestral value and accounts for a considerable share of household consumption. It should be noted that the major problem of this cassava crop has been the mosaic that has caused the significant drop in production. Currently, the situation is gradually improving following the intervention of improved cuttings introduced by FAO, international NGOs and research center like International Institute of Tropical Agriculture.

With the presence of brown streak, cassava production is only decreasing and is causing total discouragement among farming households. Corn yields $20.41 \%$ of the average household production and is grown on an average area of $57.59 \mathrm{~m}^{2}$. Following the decline in cassava production, farmers have substituted cassava for maize. Note that this last culture remains more nutritious than the first. As for the cultivation of beans, it occupies on average $44.31 \mathrm{~m}^{2}$ of surface area and gives $15.23 \%$ of the average production per household. The peanut crop gives an average production of $11.77 \%$ over an area of $57.07 \mathrm{~m}^{2}$. The rice cultivation, which gives $7.27 \%$ of the average household production, is cultivated over an area of 95.33 $\mathrm{m}^{2}$. The latter is an irrigated crop and is cultivated only in Bwegera and Kigwena where there is a sufficient number of marshes. The survey shows that $64.43 \%$ of the rice comes from the locality of Bwegera and $35.57 \%$ from the locality of Kigwena. Its production remains low, considering the opportunities that this culture presents in 
the plain of Ruzizi, in general, and in the Bufuliru community-chieftaincy, in particular. The big problem to solve for this crop is much more at the level of marketing. Agricultural inputs such as seed, hoe, spade and machete are used by $100 \%$ of households and only $4.2 \%$ of households use wage labor and $95.8 \%$ use family manual labor. By looking at the used (chemical and organic) fertilizers, the survey shows that $71.79 \%$ of households do not use fertilizers whether chemical or organic because, according to them, the land is very fertile. $17.95 \%$ of households use chemical fertilizers for rice, maize, peanut crops...for which a large quantity of these fertilizers constitute donations from international and local NGOs such as Caritas, Oxfam etc. The organic fertilizers used are mostly compost and dung.

The degree of self-consumption is very high for most of the crops grown by households. Growing beans $(80.87 \%)$, cassava $(79.49 \%)$ and maize $(65.87 \%)$ has a higher degree of self-consumption. The predominance of these crops in household consumption is justified by the fact that they are consistent with household eating habits and provide a large part of the kilocalories to the population of this study area. A small amount of this crop is market oriented. Rice is not a staple in the Bufuliru locality-chieftaincy. That's why a lot of it is market-oriented. For most of these crops, their processing is simple and inexpensive because it is done by hand except for rice and cassava to be marketed which are processed by mills. It should be noted that of $100 \%$ of households that consume maize flour, $63.04 \%$ mix with cassava flour and $36.96 \%$ do not mix, that is to say, they consume the latter in its raw state.

The survey shows that, in general terms, the locality of Bwegera produced a large quantity of the commodities that have been selected in comparison with the localities of Kingwena and Lemera. This situation can be explained by the crossing of Bwegera locality by the National Road No. 5 which facilitates the products flow towards the big centres of consumption like Uvira, Bukavu, Bugarame (Rwanda) and Cibitoke (Burundi). In this case, households in Bwegera may have a high probability of having a high income and a low rate of food insecurity than the localities of Kigwena and Lemera.

Table 4. Areas, production and average self-consumption of crops.

\begin{tabular}{lllllll}
\hline Culture & $\begin{array}{l}\text { Number of } \\
\text { household }^{\mathbf{6}}\end{array}$ & $\begin{array}{l}\text { Average area } \\
\mathbf{( m}^{\mathbf{2}} \text { ) }\end{array}$ & $\begin{array}{l}\text { Average quantity produced } \\
(\mathbf{k g}) \text { by household (1) }\end{array}$ & \% & $\begin{array}{l}\text { Average quantity sold } \\
\text { (kg) by household (2) }\end{array}$ & $\begin{array}{l}\text { Average self- } \\
\text { consumption (kg) }\end{array}$ \\
\hline Peanuts & 34 & 57.07 & 447.28 & 11.77 & 229.72 \\
\%o
\end{tabular}

Source: Authors based on the survey data

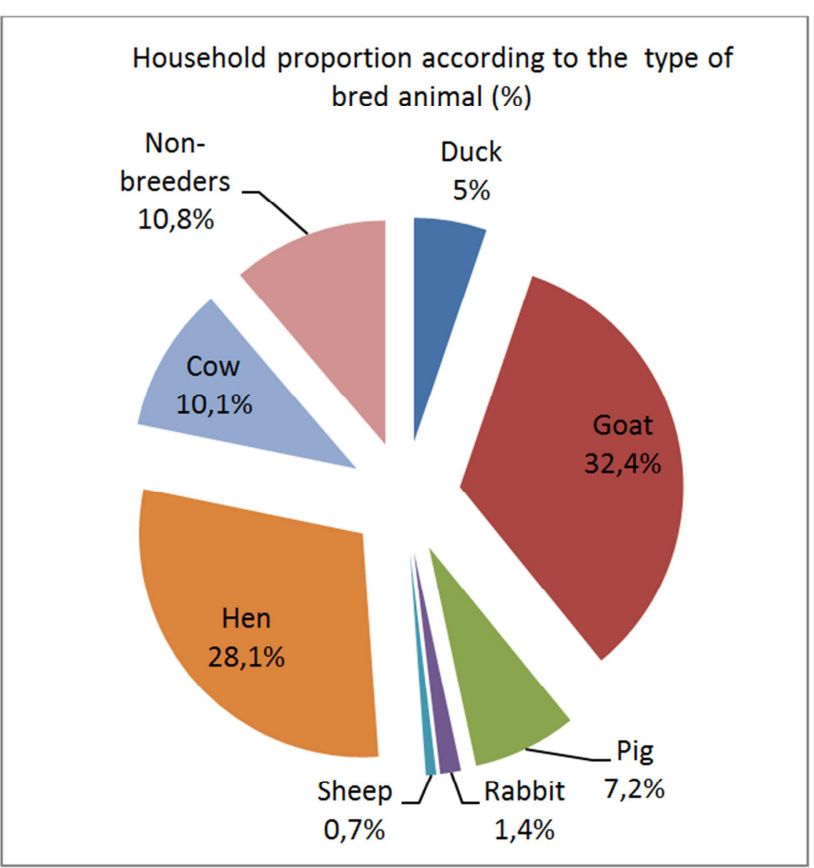

Average number of animals per household
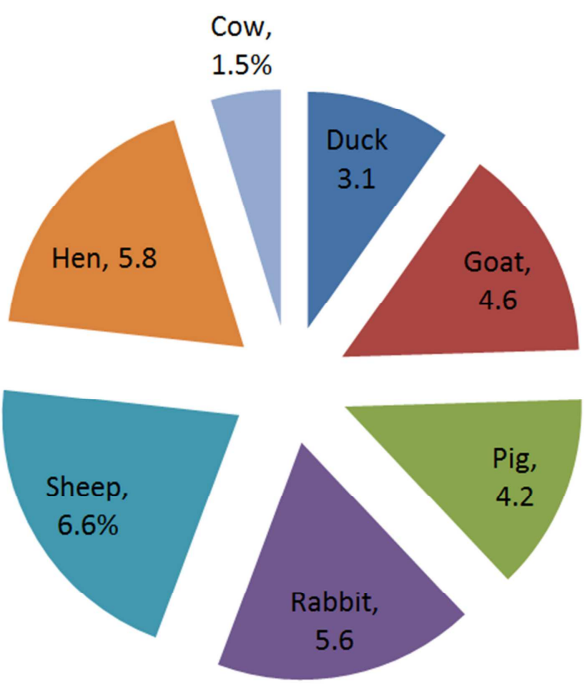

Figure 2. Household proportion according to the type of bred animal and the average number of animals per household. 


\subsubsection{Livestock Farming}

Livestock farming potential in South Kivu is largely under-exploited due to loss of earnings for various reasons [24]. According to De Failly [29], livestock farming is a sector which has obviously paid a heavy price for the conditions of insecurity, then of armed disturbances and wars which have prevailed in Kivu since 1993. The reality is obvious, a big number of large and small livestock continue to disappear because of the current wars and insecurities on all territories of South Kivu.

In view of the results of the survey (Figure 2), the goat is the animal raised by many households $(32.4 \%)$ and whose average unit number is approximately 5 goats per household. It constitutes savings for the household and accompanies cows during the dowry in the majority of ethnic groups of the South Kivu province. But for others, the dowry is fixed in term of number of the goats. The chicken also occupies a prominent place with $28.1 \%$ of households raising it with about 6 hens on average per household. The chicken is a prestigious food especially when a distinguished guest is at home. The cow is the animal of socio-cultural and economic importance compared to other animals. It is indeed a supplier of milk and organic manure. It is also a symbol of dowry among most ethnic groups in the province of South Kivu and a form of considerable savings to cope with large family expenses such as the payment of academic fees for children at the University, purchase of a plot,... However, the various wars in repetition and consequent looting, forced the cow to a modest presence in our study area where only $10.1 \%$ of the households raise it and whose average about 2 cows per household. This cow farming remains dominant in the locality of Bwegera compared to other localities. $7.19 \%$ of households raise pork. This is explained by the fact that the latter is considered much more prolific.

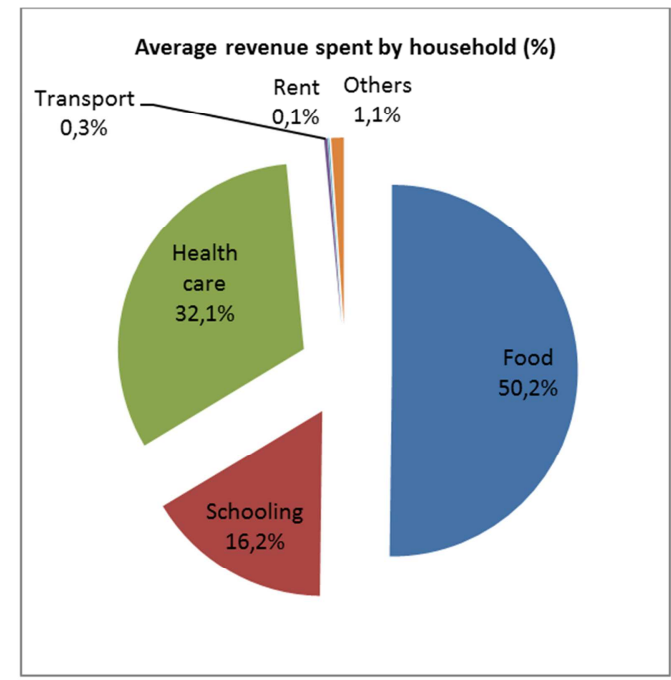

In addition, pork is considered a "strategic" animal which, because of its grunt when exposed to being captured, would not be much appreciated by looters and armed gangs (Leuven Development, 2008). Sheep, duck and rabbit are rare animals in our study area. Similarly, although prolific, the rabbit has less increasing success than the guinea pig.

The livestock farming sector faces several problems making households discouraged. These problems are the exaggerated theft, the lack of animal housing because most spend their nights with people, the lack of improved and much productive breeds, the lack of pastures, especially during the dry season, the lack of vaccines and livestock medicines, the lack of a specialized organization structure to defend the breeders' cause. In view of these problems, the non-breeders rate $(10.79 \%)$ is crucial and this rate may increase if the security situation continues to worsen in the study area.

\subsection{Household Income}

The lack of stable and sufficient income is an important vector of household food insecurity in the Bufuliru Chiefdom community. Surveys indicate that agriculture (84\%) dominates household activities in the Bufuliru locality and is the main source of income. Inadequate income from the main activity requires $48.92 \%$ of households to engage in secondary activity. This strategy of diversification of income sources is explained by the precariousness of income from agriculture. Several constraints are at the base of low income in this zone, including the difficult access to household financing, the difficult flow of products to the markets, the virtual absence of processing units, the presence of plant diseases, the presence of land conflicts, especially between breeders and farmers, cattle theft, climate change,..., are the main obstacles to generate income.

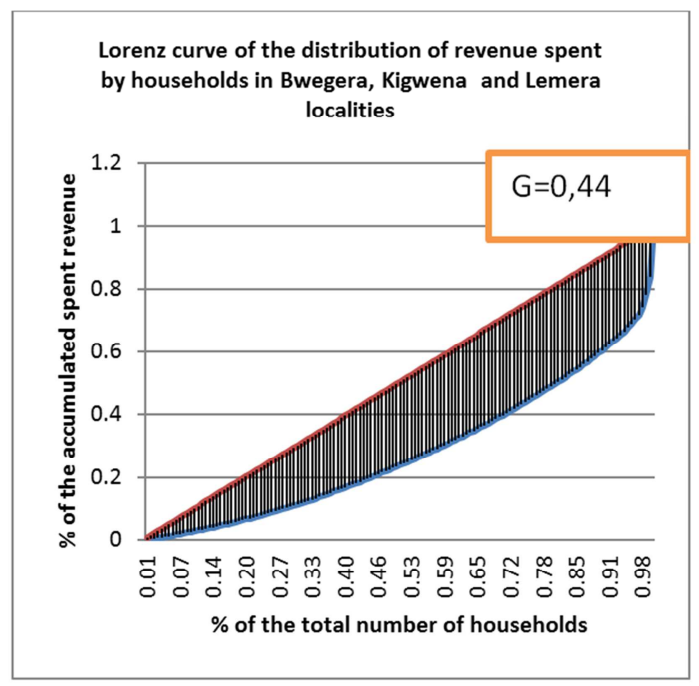

Figure 3. Monthly average revenue spent by household and income inequality.

Survey result shows that, on average, households in our study area live with US \$ 50.09 per month, with an average of 7.3 persons per household. In this sense, the income spent per person is $\$ 6.86$ per month or $\$ 0.23$ per person per day. This income is very low and is even well below the poverty line of $\$ 1.25$ per person per day. This low income may 
explain the vulnerability of households in this zone. The share of food expenditures is $\$ 25.16(50.2 \%)$ of the average total household income. School fees are low and represent an average of US $\$ 8.13(16.2 \%)$ per household. This situation explains the high rate of illiteracy $(36.69 \%)$. Medical care representing US \$ 16.10 (32.1\%) of the household budget seems very high. This situation can be explained by the presence of several diseases such as malaria (71.94\%), headaches $(4.32 \%)$, and stomachache $(5.04 \%)$.

When the Gini index is important, this means that the differences or inequalities of income spent between the populations considered are large. The Gini index, with its low income inequality, brings the Lorenz curve closer to the diagonal of perfect equality, thus reducing the lens-shaped surface between the diagonal of perfect equality and the Lorenz curve.. In our case, the Lorenz curve shows that income inequality is large, i.e. a small proportion of the population has a large share of income. The Gini coefficient $(\mathrm{G}=0.44)$ is not weak and confirms this inequality with a modal income of $\$ 56.28$ which represents the income with the highest frequency and the median income of $\$ 44.48$ which explains that $50 \%$ of the households have an income lower than $44,48 \$$ and $50 \%$ other households have an income higher than 44,48 \$.

Table 5. Weight of different products in household consumption.

\begin{tabular}{|c|c|c|c|c|}
\hline \multirow[b]{2}{*}{ Food } & \multirow{2}{*}{$\begin{array}{l}\text { International standards } \\
\text { Calorific quantity per food for kg } \\
\text { consumed (Kcal) }\end{array}$} & \multicolumn{3}{|c|}{ Household consumption baskets } \\
\hline & & $\begin{array}{l}\text { Average quantity kg/month } \\
\text { consumed by household }\end{array}$ & $\begin{array}{l}\text { Calorific quantity per day and } \\
\text { per person (kcal) }\end{array}$ & $\%$ \\
\hline Amaranth & 3740 & 2,82 & 50,2 & 4,0 \\
\hline Maize flour & 3460 & 15 & 247,1 & 19,8 \\
\hline Cassava flour & 1325 & 64,26 & 405,5 & 32,5 \\
\hline Beans & 374,9 & 12,36 & 22,1 & 1,8 \\
\hline Small fish & 33,5 & 1,85 & 0,3 & 0,0 \\
\hline Fish & 700 & 1,66 & 5,5 & 0,4 \\
\hline Rice & 3477,6 & 2,57 & 42,6 & 3,4 \\
\hline Cassava leaves & 580 & 14,45 & 39,9 & 3,2 \\
\hline Meat & 2600 & 2,65 & 32,8 & 2,6 \\
\hline Tomatoes & 200 & 4 & 3,8 & 0,3 \\
\hline Onion & 300 & 4 & 5,7 & 0,5 \\
\hline Vegetable oil & 8990 & 4 & 171,2 & 13,7 \\
\hline Total & & 144,84 & 1246,3 & 100,0 \\
\hline
\end{tabular}

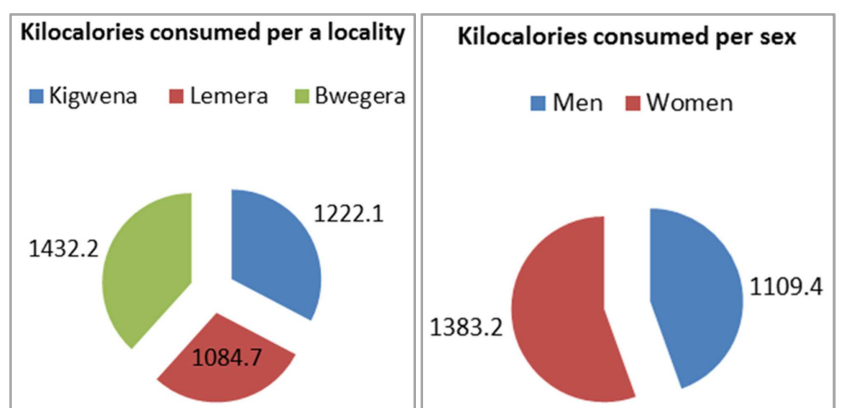

Figure. 4. Kilocalories consumed per a locality and Kilocalories consumed persex.

\subsection{Calorie Consumption Status}

Cassava flour (32.5\%) and maize flour (19.8\%) are foods that provide more than $50 \%$ of calories to households in the study area. This demonstrates the importance of these cultures in these environments again. Vegetable oil and palm oil provide respectively $13.7 \%$ and $12.9 \%$ of the kilocalories to households in the study area, which is explained by their high weighting in standards even if the quantities consumed remain low. Fish $(0.4 \%)$ are little consumed by households. This low rate of fish consumption can be explained by the existing farm ponds not maintained in these localities. A small amount of fish such as "Ndagala" and "Sambaza" fry and/or small fish come from Uvira and are very expensive on the periodic markets of these localities. Meat provides very low kilocalories to households, i.e. $2.6 \%$. This is explained by the fact that meat is expensive compared to the purchasing power of households in the study area. Even for households that practice livestock farming, the latter is savings and is rarely used for food consumption. Vegetables and leguminous plants as amaranths $(4 \%)$, cassava leaves $(3.2 \%)$, beans $(1.8 \%)$ provide very little household calories because according to the majority of respondents, eating vegetables is a lack. In this case, what food security for these households that consume too little amount of meat, fish and vegetables! The survey shows that a person consumes on average 1246.3 kcal per day which is far from the standard of $2400 \mathrm{kcal}$ set by FAO and WHO. The survey results show that $12.2 \%$ of households eat once a day and $69.78 \%$ of households eat twice. Only less than $17 \%$ of households eat 3 to 4 meals a day. Most households that eat three and / or four times a day are positive caloric households, so those who eat once and / or twice a day are negative caloric households. The average number of kilocalories consumed by households in Bwegera appears to be slightly higher compared to other localities. The high agricultural production, the presence of the National Road No. 5, its supremacy in the production of livestock, constitute so many elements that can explain a high consumption of kilocalories in Bwegera than in other localities. It follows from the survey that women consume more calories than men. This can be explained by the fact 
that women work a lot more than men, and household survival and food security are much more dependent on women. Men consider themselves leaders and are less and less visible in the activities of products transport by the back or head from field to their houses, in the marketing of agricultural products, in the agricultural products small-scale processing etc. Let us also mention that women are very present in the kitchen of which $61.87 \%$ of the households use the firewood which must be sought, for the most part, far from the village, and $38.13 \%$ use embers. This use of firewood and embers poses serious environmental problems as it is accompanied by the absence of reforestation and uncontrolled tree cutting, often resulting in erosion and soil degradation, and contributes to household food insecurity.

\subsection{Estimated Energy Need (BEE) and Household Food Security Status}

Table 6. Kilocalories consumed and Estimated Energetic Need.

\begin{tabular}{llll}
\hline Wording & Kcal consumed & EEN & Gaps \\
\hline Men & 1109,37 & 2367,12 & $-1257,75$ \\
Women & 1383,19 & 2240,4 & $-857,21$ \\
Average & 1248,28 & 2303,76 & $-1055,48$ \\
Bwegera & 1432,2 & 2375,5 & $-943,3$ \\
Kigwena & 1222,1 & 2229,4 & $-1007,3$ \\
Lemera & 1084,7 & 2306,4 & $-1221,7$ \\
\hline
\end{tabular}

Source: Survey data processing

As a reminder, equations (1) were used to calculate the BEE of the respondents. By comparing the kilocalories consumed provided by the consumption basket and the BEE, there is a largely negative average difference. This explains why the condition of household food security in the study area is very alarming, with $79.4 \%$, the gap being negative or food insecure, and only $20.6 \%$ of households whose gap is positive either in food security. The result of the survey shows that the Bwegera locality has a small difference in kilocalories compared to the other two localities. As has already been said, this locality enjoys an advantage over others.

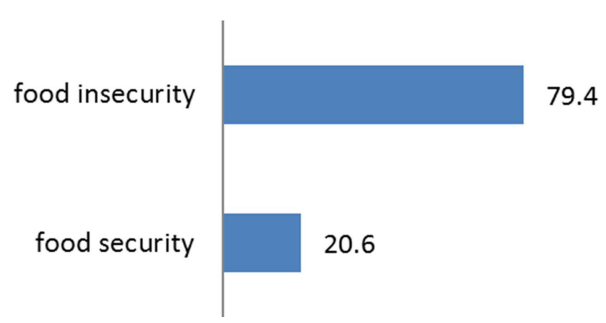

Figure 5. Household food security status (\%).

\subsection{Determinants of Food Security}

Considering the findings on the characteristics that determine household food security, the regression with household food security as a dependent variable was performed. In Table 7, the results obtained from the logistic regression were interpreted through the Xlstat 2014 software for the determinants of food security in the localities of Bwegera, Kigwena and Lemera. Overall, the estimation results make it possible to understand that not all variables are necessarily involved in the decision to be food secure for households in the different localities of the study area. These results show that the dependent variables selected are not all significant. It is observed that the variables associated with age, seniority in agricultural activity, the existence of savings in the household, food expenses, are not significant in any of the localities.

Table 7. Logistic regression results

\begin{tabular}{|c|c|c|c|c|c|c|}
\hline \multirow{2}{*}{ Variables } & \multicolumn{2}{|l|}{ Bwegera } & \multicolumn{2}{|l|}{ Kigwena } & \multicolumn{2}{|l|}{ Lemera } \\
\hline & Coeff. & P-value & Coeff. & P-value & Coeff. & P-value \\
\hline Constant & 706.52 & 0.334 & 842.093 & 0.870 & 1000.72 & 0.564 \\
\hline Household size & 116.79 & 0.491 & 127.016 & 0.341 & 315.08 & $0.043 * *$ \\
\hline Education level & 356.64 & $0.057 * * *$ & 188.856 & $0.066 * * *$ & 743.61 & $0.044 * *$ \\
\hline Gender & 243.55 & $0.081 * * *$ & 964.614 & $0.041 * *$ & 36.68 & $0.098 * * *$ \\
\hline Age & 25.46 & 0.230 & 101.003 & 0.265 & 102.68 & 0.193 \\
\hline Distance from home to market & -12.73 & $0.039 * *$ & -190.232 & 0.227 & -28.13 & 0.391 \\
\hline Stock & 332.74 & 0.311 & 569.940 & 0.876 & 443.64 & 0.411 \\
\hline Farming & 648.64 & $0.033 * *$ & 0.364 & 0.102 & 644.64 & 0.443 \\
\hline Revenue & 0.25 & $0.083 * * *$ & 5.421 & $0.068 * * *$ & 0.35 & $0.084 * * *$ \\
\hline Meal numbers/ day & 142.70 & $0.029 * *$ & 164.934 & $0.039 * *$ & 143.67 & $0.027 * *$ \\
\hline Seniority/agriculture & 2.08 & 0.925 & 48.602 & 0.783 & 3.04 & 0.725 \\
\hline Food expenses & 0.23 & 0.908 & 0.823 & 0.976 & 0.34 & 0.708 \\
\hline Savings & -568.40 & 0.318 & -920.149 & 0.781 & -564.46 & 0.418 \\
\hline Other sources of income & 689.8 & 0.151 & 667.153 & 0.126 & 646.4 & $0.071 * * *$ \\
\hline Chi-square & & 47.957 & & 30.132 & & 35.028 \\
\hline ddl & & 13 & & 13 & & 13 \\
\hline sig & & 0.000 & & 0.005 & & 0.001 \\
\hline
\end{tabular}

Source: Software Xlstat 2014. ***significant at $10 \%, * *$ significant at $5 \%, *$ significant at $1 \%$

In addition, households with a high level of education have a high probability of eating balanced meals and improving their food security. The high number of meals eaten improves the state of household food security. The more a household has multiple sources of income in Lemera, the probability of being food secure is high. This can be explained by the fact that life in the locality of Lemera was centered around the Reference Hospital of the $8^{\text {th }}$ community of penthecotist 
churches in central africa which has for a long time had a great reputation at local and regional level. In the locality of Lemera, the larger the household size is, the more the household is food secure because some members of the household can intervene in the family workforce and can work in other sectors to increase household income. The high income held by the household improves its state of food security and the household headed by women are more food secure than those led by men. Livestock farming, the distance between home and the market significantly explains the food security situation in the locality of Bwegera in view of the importance of this activity in this locality compared to the others. Moreover, this locality is located on the National Road $n^{\circ} 5$ which allows the easy access of the population to different rural markets (Sange, Luvungi) urban (Uvira, Bukavu) and foreign ones (Bugarama in Rwanda, Cibitoke and Rugombo in Burundi).

\section{Discussion}

From the results obtained, the household food security in the three localities of the study is explained significantly by the level of study, the gender, the income, the number of meals. In addition, livestock farming, the distance between the market and the home were factors that significantly condition the probability of a household being food secure only in the locality of Bwegera whereas household size and existence of other income sources within the household significantly affect food security only in the locality of Lemera. These results corroborate those found by Kinimo [26], who shows that household size, educational attainment, and gender were factors in the malnutrition of central and eastern Ivory Coast. The results of the study show that the level of education has a positive and significant impact on household food security in the three localities studied. This coincides with the study by Lukuli [30], who shows that there is a direct causality between education and poverty and therefore food insecurity. For Zoyem et al. [24], factors of various kinds can expose households in Burundi to food insecurity, including the level of education. The number of meals taken per day significantly increases the possibility of improving food security. As showed by Bucekuderwa and Mapatano [25], family meals being the main source of calorie supply, it is obvious that the more one eats, the more the calorie intake increases and thus the probability of escaping the vulnerability of food insecurity increases. The sign of household size is consistent with what is observed in the literature $[31,32]$ and was significant only in the Lemera group. Unlike the work of Bucekuderwa et Mapatano [25], which shows that female-headed households will tend to be more vulnerable to insecurity and vice versa, the survey results show that female-headed households are highly likely to be food secure because they are the guarantors of household food security and are found in all the jerseys of agricultural value chains $[16,14]$ at the level of production, marketing and even cooking. As Bucekuderwa et Mapatano [25], the income variable is significant and implies that a household's food insecurity is aggravated by each decrease in a unit of income. The results of the survey show that livestock farming is a positive and significant contributor to food security in the Bwegera grouping and is therefore an important element to integrate into smallholder agriculture to improve its performance in Bwegera and increase its impact on food security. Livestock farming is an important endowment as a means of saving in peasant nature and household recourse [29] and the ability to access sufficient food is highly dependent on the availability of livestock [25]. The distance between the house and the market explains negatively and significantly food security in the locality of Bwegera. The longer this distance is, the more difficult is for households to access food and evacuate their agricultural products with difficulty to markets. Possession of other sources of income by households in Lemera has positively and significantly explained food security. This diversification of sources of income has long been considered by the literature as one of the coping strategies in the face of food insecurity [33], although the share of aid from families and friends is still a significant social capital.

\section{Conclusion}

The results of this study showed that the areas cultivated are low even if the opportunities in terms of arable land exist, the agricultural production is weak and the level of selfconsumption remains high for the main crops in the study area. The potential for livestock farming remains under-exploited and keeps on taking heavy war tolls and insecurities in these localities. Agriculture is the main source of income and is unequally distributed among households. Cassava and maize remain the main crops that provide a large contribution in terms of calories consumed by households. On average, there was a caloric deficit consumed by all households in three localities under study, and women consume more calories than men. The majority of households in these three localities are food insecure with negative differences between the amount of kilocalories consumed and the Estimated Energy Need. Factors that significantly explained food security (level of education, gender, income, number of meals, livestock farming, distance from home to market, household size, and the existence of other income sources) are the levers on which the different interventions of the actors (State, NGOs, Donors,...) will be able to rely on to reach a level of food security more effective in the three localities under study according to the different policies and the socio-economic programs that will be put in place by these different actors whose search for peace, the distribution of wealth and the consolidation of democracy are the elements without which the measures advocated will have no considerable added value in the fight against food insecurity. In this case, it is necessary to encourage large-scale production through access to new technologies, access to food, education and financing, structuring and strengthening the capacities of farmers' organizations, diversification of activities and the revival of the livestock farming sector and its integration into the cropping system, access to resources by 
women, the development of agricultural markets for products and inputs. It should be noted that these mechanisms will have to be followed by accompanying policies to lead to household food security in these three localities under study.

\section{Acknowledgements}

Authors acknowledge the Evangelical University in Africa (EUA) for manifold support to this work which was graciously been funded through the University project on improvement of research and teaching quality funded by Pain pour le Monde.

\section{References}

[1] A. Amsoms \& W. Marivoet (2010), "Socio-economic profile of South Kivu and future lines of research". In: S. Marysse, F. Reyntjens \& S. Vandeginste. (eds.). Africa of the Great Lakes: Yearbook 2009-2010. Paris: The Harmattan, 259-271. (In French)

[2] A. Sen (1981), "Poverty and famines. An Essay on Entitlement and Deprivation". International Labor Organization.

[3] FAO (1996), "Rome Declaration on World Food Security and Plan of Action of the World Food Summit", 1317 November 1996, Rome Italy, 1996-a, 48p. (In French)

[4] FAO, IFAD \& WFP (2015), "The State of Food Insecurity in the World 2015". 2015 International Goals for Hunger Reduction: Uneven Progress. Rome, FAO (In French).

[5] N. Dembélé (2001), "Food Security in Sub-Saharan Africa: What a Realization Strategy, Support Project for the Decentralized Information System of the Agricultural Market". PASIDMA, Mali Chamber of Agriculture. Bamako, February 2001 1-4P. (In French)

[6] CE \& CTA (1998), "Community Strategy for Food Security and ACP Countries". Seminar on Food Security, Brussels, European Commission, Technical Center for Agricultural and Rural Cooperation, 1997, 20-23 October, 24-27 November, 811 December, 1998, 94p. (In French)

[7] Human Resources Development Canada (HRDC) (2002), "Food insecurity in Canada 1998-1999". (In French)

[8] FAO (2008), "Introduction to the concept of food security". EC-FAO Program (Food Security: Information for Action: Practical Guides. (In French)

[9] D. Ouédraogo, K. Moussa \& B. Kienou (2007), "Food insecurity, vulnerability and poverty in rural Burkina: an approach in terms of energy consumption". De Boeck Superior | "Worlds in development" 2007/4 $\mathrm{n}^{\circ} 140$ | pages 65 to 84 (In French)

[10] G. Azoulay, \& J. Dillon (1993), "Food Security in Africa, Handbook of Analysis and Strategy Development". Karthala Edition, 296p. (In French)

[11] V. Tarasuk, A. Mitchell \& N. Dachner (2013), "Household Food Insecurity in Canada, 2012". Toronto. Retrieved from $\mathrm{http}: / /$ nutritionalsciences.lamp.utoronto.ca/.

[12] FAO (2009), "World agriculture by 2050". Rome. Italy. (In
French)

[13] B. Parmentier (2008), "Agriculture: the new world order and medium and long-term prospects". Geoeconomics, 46, (3), 6185. doi: 10.3917/geoec.046.0061. (In French)

[14] S. Vwima (2014), "The role of the border trade of food products with Rwanda in provisioning the urban households of Bukavu town". (PhD Thesis). University of Liege/Gembloux Agro-Bio Tech, Belgium. (In French)

[15] WFP, UNICEF, ANSD (2008), "Impact of price increases on the food security of urban populations". Final report. (In French)

[16] J-L. Mastaki (2006), "The role of market bottlenecks in the adoption of agricultural innovations among food producers in South Kivu (East of R. D. Congo)". PhD thesis Faculty of Agricultural Sciences of Gembloux (Belgium). (In French)

[17] WFP (2014), "In-Depth Analysis of Food Security and Vulnerability (CFSVA)". DRCongo. (In French)

[18] MICS (2010), "Multiple Indicator Cluster Survey". MICS2010 (In French).

[19] Integrated Framework for Food Security Classification (IPC) in East and Central Africa, December 2012 (In French).

[20] J-P. Chausse, T. Kembola \& R. Ngonde (2012), "Agriculture: Cornerstone of the DRC's Economy", in J. Herderschee, D. Mukoko Samba \& M. Tshimenga Tshibangu (editors). "Resilience of an African Giant: Accelerating Growth and Promoting Employment in the Democratic Republic of Congo". Volume II: Sector Studies, MEDIASPAUL, Kinshasa, pages 1-97 (In French).

[21] P. Lebailly, B. Michel \& R. Ntoto (2014), « What agricultural development for the DRC". Conjoncture. (In French)

[22] S. Vwima, J-L. Mastaki, P. Lebailly. (2013), "The role of border trade in food with Rwanda in the household supply of the city of Bukavu (South Kivu Province)". In The notebooks of the Third World Association, ${ }^{\circ} 28$. P. 27-41. (In French)

[23] UNDP (2010), "Note on the political and socio-economic situation in South-Eastern". (In French)

[24] J. P. Zoyen, E. Diang'a, Q. Wadon (2008), «Measures and determinants of food insecurity in Burundi according to the caloric intake approach". The African Statistical Journal. vol. 6. (In French)

[25] C. Bucekuderhwa \& S. Mapatano. (2013), "Understanding the dynamics of vulnerability to food insecurity in South Kivu", VertigO - the electronic journal in environmental sciences [Online], Special Issue 17| September 2013, posted on September 12, 2013, accessed on May 09, 2017. (In French) URL: http://vertigo.revues.org/13819; 10.4000/vertigo.13819. (In French)

[26] Y. R. Kinimo (2013). "Determinants of under-nourishment of households in Côte d'Ivoire: the case of the Center and CenterEst regions". European Scientific Journal. vol 9 No. 14. Kivu, 1st Semester 2010. New York: UNDP. (In French)

[27] C. Hurlin (2003), "Econometrics of qualitative variables". Unpublished, University of Orleans, France. (In French)

[28] C. Blanchet, C. Plant, L. Rochette (2009). "Food consumption and nutritional intake of Quebec adults". National Institute of Public Health of Quebec. (In French) 
[29] D. De Failly (2000), "The economy of South Kivu 1990-2000: profound changes hidden by a breakdown". In: S. Marysse. \& F. Reyntjens. (eds.). "Africa of the Great Lakes": Yearbook 1999-2000. Paris: The Harmattan, 163-192. (In French)

[30] Lukuli (2006). Poverty Measurement and Analysis in South Kivu, LEAD, PIC Project "Dynamics of Productive Sectors and Integrated Rural Development", CUD, Discussion Paper, Mimeo, LEAD, UCB. (In French)

[31] A. Abdulai \& A. Crole Rees (2001), "Determinants of income diversification among rural households in Southern Mali". Food Policy, 26, 437-452.

[32] F. Wouterse \& J. E. Taylor (2008), "Migration and Income Diversification: Evidence from Burkina Faso". World Development vol. 36, No. 4, pp. 625-640.
[33] J. K. Sesabo \& R. S. J. Tol, (2005), "Factors affecting income strategies among households in Tanzania coastal villages: implications for development conservation initiatives". Working paper FNU-70.

[34] A. M. Roza \& H. M. Shizgal (1984), "The Harris Benedict equation reevaluated: resting energy requirements and the body cell mass". American Journal of Clinical Nutrition. vol. 40 (1): 168-182.

[35] Institute of Medicine of National Academies. Dietary Reference Intakes (DRIs). The essential guide to nutrient requirements. The National Academies Press. Washington. 2006. (In French)

[36] WFP, Quarterly Newsletter on Food Security in the DRC, Issue 3/2011-4 ${ }^{\text {th }}$ Quarter 2011. 